$\begin{array}{ll}\text { le portiQue } & \text { Le Portique } \\ \text { Revue de philosophie et de sciences humaines }\end{array}$

$18 \mid 2006$

Heidegger. La pensée à l'heure de la mondialisation

\title{
La grande tâche de la poésie
}

\section{Michel Deguy}

\section{OpenEdition}

Journals

Édition électronique

URL : https://journals.openedition.org/leportique/826

DOI : 10.4000/leportique.826

ISSN : $1777-5280$

\section{Éditeur}

Association "Les Amis du Portique"

Édition imprimée

Date de publication : 1 septembre 2006

ISSN : 1283-8594

\section{Référence électronique}

Michel Deguy, "La grande tâche de la poésie », Le Portique [En ligne], 18 | 2006, mis en ligne le 15 juin 2009, consulté le 20 février 2023. URL : http://journals.openedition.org/leportique/826 ; DOI : https:// doi.org/10.4000/leportique.826

Ce document a été généré automatiquement le 20 février 2023.

Tous droits réservés 


\title{
La grande tâche de la poésie
}

\author{
Michel Deguy
}

Commentaire du livre de Philippe LACOUELABARTHE, La Politique du poème, Paris, Galilée, 2002

1 À la page 120 de son livre La Politique du poème, Philippe Lacoue-Labarthe cite Heidegger disant de Hölderlin qu'« il n'est pas encore devenu puissance dans l'Histoire de notre peuple ».

2 Si c'est ça l'affaire, où en sommes-nous, « nous », « nous autres Français »? La dernière fois que quelque chose de tel a eu lieu, le «devenir puissance d'un poème/poète dans l'Histoire du peuple ", ça s'est appelé Victor Hugo. L'âge de ce devenir-puissance fut donc clos en 1885, il y a quelque 120 ans. La légende du siècle, Victor Hugo, qui a lui seul était le vers, disait Mallarmé, et l'accusateur du régime impérial, puis le sénateur de la République, tenant la politique du poème et le poème de la politique, cette légende se refermait. De médiation entre le peuple et la poésie, de " demi-dieu », il n'y eut plus. Le devenir «action restreinte » avec Mallarmé sépare «l'Histoire de notre peuple» d'une possibilité pour que le poème, et le nom d'un Poète, «devienne puissance ».

Or, que la différence passant à l'in-différence se soit encore détériorée jusqu'à la catastrophe de l'abandon hostile (que vient sceller et non réparer l'acculturation sociale culturelle de la poésie, je n'en prends à témoin que ce seul fait, précisément « incontestable » : le nom propre de la plus récente phase du Dichten, autrement dit de la dernière fois où l'art et les arts, le Poème, a pris figure de puissance dans l'Histoire, bref: le surréalisme, tentative d'insurrection nationale, internationale et cosmopolitique, voici qu'en quelques décennies son nom propre, en régime d'épithète («c'est surréaliste!») en est venu partout, pour tous, je veux dire médiatiquement, populairement, à signifier le faux sens, ou le non-sens, le contresens ou le n'importe quoi de la stupidité.

4 Que si donc l'avenir du xxI siècle est le surmontement du nationalisme, l'arrachement des peuples à l'ethnie, à la " purification ethnique ", donc à contresens de ce que fut la poésie comme chant d'identification "nationale ", alors on peut douter que la poésie, privée de tout devenir puissance, puisse jouer un rôle dans ce devenir, dans cette phase 
de l'anthropomorphose... (« le dieu qui peut nous sauver », ou par vicariance son demidieu, ne semble plus « pouvoir prendre la figure du Poète »).

\section{RÉSUMÉS}

Commentaire du livre de Philippe lacoue-LABARTHe, La Politique du poème, Paris, Galilée, 2002

«La grande tâche de la poésie ». Comprendre ce qu'aura été le grand Romantisme européen, ces deux siècles d'un âge immense de la poésie (Dichtung) est une tâche difficile, nécessaire à notre orientation après le romantisme, autrement dit après les révolutions. Heidegger croyait pouvoir écrire, reprenant le grand motif romantique de la relation privilégiée, " essentielle ", du poète et de son peuple (Volk), que «Hölderlin n'est pas encore devenu puissance dans l'Histoire de notre peuple. »Comment prendre acte du (c'est-à-dire penser le) décès de cette croyance?

Deux formules d'Adorno proposent deux «paramètres " pour appréhender l'« obscurité » de nos temps, susceptibles de nous aider dans la (ré)orientation (Kant) de la pensée. L'une parle de «vaine tentative" (de la musique), l'autre de "prière démythifiée ». Michel Deguy pour frayer du sublime et de la transcendance contemporains cherche à les faire parler davantage. Le sublime affecte la transcendance moderne; la "sublimation", dans la suite, peut-être, de l'élévation baudelairienne, est tâche quotidienne. Profaner, c'est déposer - et ainsi garder auprès. Profaner, pour une transcendance active. Grandes tâches de la poésie?

Michel Deguy, "The great task of poetry". To understand what the great European romanticism has been, those two centuries of an immense age of poetry (Dichtung), is a difficult task. It is nevertheless necessary to our orientation in the postromantic, that is to say, the postrevolutionary age. Heidegger thought that he was entitled to write and re-use the celebrated motive of the "essential" and "privileged" relation between the poet and his people. Heidegger thought that "Hôlderlin has not yet become a power in the history of our people". How can we, today, acknowledge, that is to say, think, the demise of such a view of the function of the poet? Two formulae offered by Adorno can provide parameters with which we may apprehend the obscurity of our times and help re-orient our thought (Kant)...Michel Deguy's is an attempt to reach the contemporary sublime and make its transcendence speak, so to speak. Whilst the sublime affects modern transcendence, sublimation, in the aftermath of its Baudelerian elevation, remains a daily task. To desecrate is to bring down and thus keep close that which is desecrated. To desecrate in order to make active all transcendence. Great tasks of all future poetry?

"La gran tarea de la poesía". Difícil resulta entender lo que habrá sido el gran romanticismo europeo, aquellos dos siglos de una fastuosa época de la poesía (Dichtung); sin embargo su comprensión es necesaria a nuestra orientación después del romanticismo, o sea después de las revoluciones. Heidegger se pensaba autorizado a escribir, repitiendo el gran motivo de la relación privilegiada, « esencial », del poeta y de su pueblo (Volk), que «Hölderlin todavía no se ha convertido en potencia en la historia de nuestro pueblo. » Cómo tomar acto (es decir pensar) el fallecimiento de esta creencia?

Dos fórmulas de Adamo proponen dos parámetros para entender la «oscuridad» de nuestros tiempos; podrían ayudarnos en la (re)orientación (Kant) del pensamiento. La primera trata de « vano intento » (de la música), la otra de la « oración desmitificada ». Michel Deguy para tratar 
de lo sublime y de la trascendencia contemporáneos intenta entenderlos mejor. Lo sublime afecta la trascendencia moderna ; la «sublimación, quizás siguiendo la « elevación » de Baudelaire, es tarea cotidiana. Profanar, es depositar y conservar con uno mismo. Profanar, para una trascendencia activa. Será una de las grandes tareas dela poesía?

"Die grosse Aufgabe der Dichtung". Wie soll man den europäischen Romantismus verstehen? Was bedeuten diese 2 Jahrhunderte der Dichtung? Schwierige Aufgabe, aber wie kommt man umhin? Heidegger übernimmt das romantische Motiv der Sonderbeziehung, der „wesentlichen“ Beziehung zwischen dem dichter und seinem Volk und glaubt zu erkennen, dass Hölderlin in der Geschichte seines Volkes noch nicht zur Macht geworden ist".

Michel Deguy versucht das Erhabene und die Transzendenz zu erforschen. Das Erhabene, das Sublime, wirke auf die moderne Transzendenz. Die „Sublimierung“ sei alltägliche Aufgabe. Profanieren sei die Heiligtümer zu Boden zu werfen, sie auf gleicher Ebene anzuschauen. Für eine aktive Transzendenz.

\section{AUTEUR}

MICHEL DEGUY

Michel Deguy est universitaire, écrivain et poète. Il est directeur de la revue Po\&sie (Belin, $27^{\mathrm{e}}$ année) et membre des Temps modernes. Il est le président de Conseil d'administration du Collège International de Philosophie. Son œuvre poétique est édité principalement chez Gallimard (3 volumes, coll. Poésie/Gallimard) et au Seuil. 